Applicants should write to the Headmaster, Charterhouse, Godalming, Surrey GU7 2DJ, England, UK, with a clear statement of their proposed field-work and the amount of grant requested. The sum normally available each year is up to $f 1,000$, and this total may be shared between several applicants.

\section{Donations}

Donations to the Fund will be warmly welcomed in the interests of increasing its usefulness and capability of helping qualified young scientists to do valuable field- work. They should be sent to The Clerk to the Governing Body, Charterhouse, Godalming, Surrey GU7 2DJ, England, UK, in the form of cheques made payable to 'The Bursar, Charterhouse' and endorsed 'For the Oleg Polunin Memorial Fund'.

\title{
Marine Debris and Fishing off Irian Jaya
}

Interviews with 'traditional' fishermen in Jayapura, Irian Jaya, Indonesia, have revealed that debris present in the sea has a negative impact on their fishing. In a particular case cited, the debris originates mostly from a municipal dump on a coastal cliff.

These traditional fishermen mainly use gill-nets and hook-and-line means to provide for their families. Sixteen persons were questioned about the impacts of waste on their fishing. All of them noticed waste in their usual fishing locations - consisting mainly of plastic bags, plastic bottles, and tin cans. They all agreed that the amount of waste is increasing with time. The impacts, as related by the fishermen, can be described as either directly or indirectly interfering with fishing.

The direct interference with fishing is illustrated by the hooking of plastic bags while trolling, or by a variety of objects entering the gill-nets when these are anchored for a few hours. The offending objects are most often plastic bags and glass or plastic bottles. These direct impacts include the cases where the net is torn or the hook is lost because of debris. This produces a lower fishing-yield (fewer fish are caught) and hence a lower income.

The indirect interference with fishing can be illustrated by examples varying from propeller entanglements, injuries sustained while walking barefoot on sand bars or while digging for shellfish, needs to change fishing locations or fishing gear (often against their best economic interest) because of the presence of wreckage or waste, and may include cleaning and/or repairing of nets. These indirect interferences cause a loss of income by increasing expenditures (e.g. for gear or engine repairs) or by increasing the amount of time spent on fishing-related activities (such as changing locations, cleaning or repairing nets and boat engines).

For fishermen living at the subsistence level, a slight decrease in income or fishing yield can have a major impact on their lives. In this case it may encourage them to adopt increasingly popular but destructive (and easier to use) fishing methods such as fishing with explosives or with cyanide - hence promoting further degradation of the coastal environment. The repercussions of this can be serious in South-east Asia, for instance, where an estimated 25 million people are directly dependant upon traditional marine fisheries for their livelihood (Smith, 1979).

\section{REFERENCE}

SMITH, IAN R. (1979). A research framcwork for traditional fisheries. Studies and Reviews, ICLARM Studies and Reviews No. 2, International Centre for Living Aquatic Resources Management, Philippines: [not available for checking].

ANNE D. NASH c/o WWF Irian Jaya

P.O.Box 525

Jayapura 99001

Irian Jaya

Indonesia.

\section{Contaminants in the Environment}

The University of Siena, Italy, is organizing a 2-weekslong 'Summer School for a Multidisciplinary Assessment of Environmental Risks for Human Health, lasting from 7 to 19 October 1991.

Topics will include:

- Distribution, levels, and fate;

- Comparative aspects of metabolism and toxicity;

- Detoxication strategies;

- Damage to biological structures; and

- Pesticides and risks for human health.

Food, lodging, and travel expenses will be provided for 15 Italian students; food, lodging, and part of travel expenses, will be provided for 15 foreign students.

Normally, a degree in Medicine or Biology is required, although possessors of degrees in related fields will also be considered. The official language will be English.
For due consideration, forward as quickly as possible your application, curriculum vitae, list of publications, letter(s) of recommendation, and a brief abstract regarding one of the above School topics (or your personal research) for possible short presentation during the School, to:

\section{ARISTEo ReNZoni, Professor Dipartimento di Biologia Ambientale Universita di Siena Via delle Cerchia 3 53100 Siena Italy.}

Telephone 0577-298831

Fax 0577-298860 Telex 572459 UNIVSI I. 